\title{
The role of sex and age in the architecture of intrapopulation howler monkey-plant networks in continuous and fragmented rain forests
}

Julieta Benitez-Malvido, Ana Paola Martínez-Falcón, Wesley Dattilo, Ana María González-DiPierro, Rafael Lombera Estrada, Anna Traveset

We evaluated the structure of intrapopulation howler monkey-plant interactions by focusing on the plant species consumed by different sex and age classes in continuous and fragmented forests in southern Mexico. For this we used network analysis to evaluate the impact of fragmentation on howler population traits and on resource availability and food choice. A total of 37 tree and liana species and seven plant items (bark, immature fruits, flowers, mature fruits, immature leaves, mature leaves and petioles) were consumed, but their relative consumption varied according to sex and age classes and habitat type.

Overall, adult females consumed the greatest number of plant species and items while infants and juveniles the lowest. For both continuous and fragmented forests, we found a nested diet for howler monkey-plant networks: diets of more selective monkeys represent subsets of the diets of other individuals. Nestedness was likely due to the high selectivity of early life stages in specific food plants and items, which contrasts with the generalized foraging behaviour of adults. Information on the extent to which different plant species and primate populations depend on such interactions in different habitats will help to make accurate predictions about the potential impact of disturbances on plant-animal interaction networks. 
1

RRH: Primate-plant networks

2

3 The role of sex and age in the architecture of intrapopulation howler monkey-

4

5 Julieta Benítez-Malvido ${ }^{1, *}$, Ana Paola Martínez-Falcón ${ }^{1,2}$, Wesley Dáttilo ${ }^{3}$, Ana M. González-Di

6

Pierro $^{4}$, Rafael Lombera-Estrada ${ }^{4}$ and Anna Traveset ${ }^{5}$

7

$8{ }^{1}$ Laboratorio de Ecología del Hábitat Alterado, Instituto de Investigaciones en Ecosistemas y

9 Sustentabilidad, Universidad Nacional Autónoma de México (UNAM), Morelia, Michoacán, 10 Mexico.

11

12

${ }^{5}$ Institut Mediterrani d'Estudis Avançats (CSIC-UIB) Esporles, Mallorca Illes Balears Spain.

Julieta Benítez-Malvido ${ }^{1}$

24

Antigua Carretera a Pátzcuaro 8701, Ex-Hacienda de San José de la Huerta, CP 58190, Morelia, Michoacán, México. 
Email: jbenitez@cieco.unam.mx

27 Abstract We evaluated the structure of intrapopulation howler monkey-plant interactions by

28

29

30

31

32

focusing on the plant species consumed by different sex and age classes in continuous and fragmented forests in southern Mexico. For this we used network analysis to evaluate the impact of fragmentation on howler population traits and on resource availability and food choice. A total of 37 tree and liana species and seven plant items (bark, immature fruits, flowers, mature fruits, immature leaves, mature leaves and petioles) were consumed, but their relative consumption varied according to sex and age classes and habitat type. Overall, adult females consumed the greatest number of plant species and items while infants and juveniles the lowest. For both continuous and fragmented forests, we found a nested diet for howler monkey-plant networks: diets of more selective monkeys represent subsets of the diets of other individuals. Nestedness was likely due to the high selectivity of early life stages in specific food plants and items, which contrasts with the generalized foraging behaviour of adults. Information on the extent to which different plant species and primate populations depend on such interactions in different habitats will help to make accurate predictions about the potential impact of disturbances on plant-animal interaction networks. 
54

55

56

57

58

59

60

61

62

63

64

65

66

67

68

\section{Introduction}

Trophic interactions among species constitute a central topic in ecology (Petchey, Morin \& Olff, 2009). Some studies have evaluated how feeding relationships vary within populations (Bolnick et al., 2003). Often within the same population we can find both more selective (those that feed off a few plant species) or more opportunistic (those that feed off many plant species) individuals (Bolnick et al., 2003; Araújo et al., 2008, 2010; Pires et al., 2011). During the development and growth of an organism, food requirements often change quantitatively and qualitatively principally because of metabolic costs, sex- and age-related preferences and foraging ability (Stevenson, Pineda \& Samper, 2005). In addition, consumer growth can be accompanied by shifts in habitat use, which may result in changes in food availability, constraining the consumer capacity to exploit different types of resources (Bolnick et al., 2003; Petchey, Morin \& Olff, 2009). According to the "Optimal foraging theory", individuals consume a subset of potential resources depending on the resource and individual traits; in this sense, individuals always eat the most valuable resources. When preferred resources are scarce, individuals can eat unutilized resources (Marshall \& Wrangham, 2007; Araújo et al., 2008, 2010; Araújo, Bolnick \& Layman, 2011).

An important ecological interaction in the Neotropics occurs between primates and the plant species they consume and disperse (Rivera \& Calmé, 2006). Primate species such as howler monkeys (Alouatta spp.) have a flexible diet (e.g., leaves, fruits, flowers, and bark) that allows them to persist in human-disturbed habitats (Marsh \& Loiselle, 2003). Groups of howler monkeys including infants, juveniles and adults, like some other primate species (e.g., 
Chiropotes spp. and Saguinus spp.), are able to cope with changes in resource availability within fragmented habitats through behavioural adjustments (e.g., food choice and foraging activity) (Jones, 2005; Isabirye-Basuta \& Lwanga, 2008). Recent studies have shown that the degree of dietary variation in A. pigra is affected by both environmental (i.e., forest fragment size) and social (i.e., group size) factors (Dias \& Rangel-Negrín, 2015). In fact, the persistence of primate populations and/or species in forest fragments largely depends on their ability to adjust their diet (Rivera \& Calmé, 2006).

Several studies have used tools derived from network analysis to describe the dietary variation found in populations of animals with a focus on individual-based plant-animal networks (Pires et al., 2011; Tinker et al., 2012; Cantor et al., 2013). Recently, it has been shown that intrapopulation primate-resource networks are highly nested: diets of specialist individuals are a subset nested within the diets of generalist individuals (Dáttilo et al., 2014). There is no information, however, about potential factors determining such network structure. In this study, we used a network approach to investigate the structure of individual-based howler monkeyplant networks and their underlying mechanisms. The application of network theory allows the recognition of non-random patterns of interactions in food webs (Bascompte \& Stouffer, 2009) and, in our case, the identification of the role of each individual within a food web based on the roles of all individuals within preserved and disturbed habitat conditions (continuous and fragmented forests). Moreover, a network approach in the study of primate diets enables us to assess the level of selectivity of an individual towards using plant species in a resource-limited environment such as small forest fragments.

To answer the question of what is driving diet selectivity and nestedness in howler monkey populations, firstly we assessed differences in resource availability (i.e., sampling of 
102 food trees and lianas) between continuous and fragmented rain forests. Secondly, we

103 hypothesized that nestedness in howler monkey-plant networks results from the most selective 104 age and sex class (male and female infants) feeding on a subset of the broader diet of another age 105 and sex class (male and female adults). We used howler monkeys' age and sex class to analyse 106 consumer-plant interaction, because these categories have shown differences in behaviour and 107 foraging patterns in primates as well as in other mammals (Brent et al. 2001; Fuentes108 Montemayor et al. 2009; Stevenson, Pineda \& Samper, 2005). For instance, species in the 109 Ateline have shown differences between the sexes in diet. Adult females of spider monkeys 110 (Ateles geoffroyi) eat live and decaying wood (e.g., Licania platypus trees) more often than do 111 adult males, possibly to satisfy their mineral (e.g., sodium and/or calcium) requirements during 112 pregnancy and lactation (Chaves, Stoner \& Arroyo-Rodríguez, 2012); by contrast, adult females 113 of black howler monkeys (A. pigra) are less active and feed mostly on fruits of high energy 114 content when lactating (Dias \& Rangel-Negrín, 2015). Moreover, fruit selection could differ 115 between sexes and age classes within primate populations, with adult individuals consuming the 116 largest seeds/fruits within a plant species (e.g., Lagothrix lagothricha in Stevenson, Pineda \& 117 Samper, 2005). Considering the postulates of the optimal foraging theory, in the absence or scarcity of their preferred resources in forest fragments, howler monkeys might consume a subset

119 of the plant species consumed in continuous forests, which maintains the nestedness in both 120 habitat types. From a conservation viewpoint, this information is useful if certain habitat

121 elements such as forest fragments are to be employed effectively in the conservation of primates 122 attention will need to be paid to their diet requirements. 
125

126

127 (16 $07^{\prime} 58^{\prime \prime} \mathrm{N}, 90^{\circ} 56^{\prime} 36^{\prime \prime} \mathrm{W}, 120 \mathrm{~m}$ elev.). Forest conversion has reduced the original forested

128

129

130

131

132

133

134

135

136

137

138

139

140

141

142

143

144

145

\section{STUDY AREA AND HABITAT TYPES}

The research was conducted at the Lacandon rain forest, Chiapas, in southeastern Mexico area $(500,000 \mathrm{ha})$ by two-thirds in the last 40 years (De Jong et al., 2000). Nevertheless, this region encompasses the largest remaining portion of tropical rain forest in Mesoamerica (Medellín, 1994). The primary vegetation type is lowland tropical rain forest, reaching up to 40 $\mathrm{m}$ in height in alluvial terraces. The temperature averages $23.9^{\circ} \mathrm{C}$, and annual rainfall is 2881.2 mm (González-Di Pierro et al., 2011). The study was conducted in two areas of lowland tropical rain forest separated by the Lacantún River: the Marqués de Comillas region (MCR, eastern side of the river) and the Montes Azules Biosphere Reserve (MABR, western side). The protected area of the MABR consists of $3310 \mathrm{~km}^{2}$ of mature undisturbed forest. We selected three forest fragments occupied by black howler monkeys within the MCR area (one fragment of 6 ha and two fragments of 3 ha in area). Each fragment has its own independent howler monkey group. Fragments were isolated by 1 to $7 \mathrm{~km}$ from each other. All fragments have been isolated from continuous forest for at least 20 years (González-Di Pierro et al., 2011). In the continuous forest within the MABR we selected three sites used by three different howler monkey groups that were separated by $2 \mathrm{~km}$ from each other. Although howler monkeys have been observed crossing cattle pastures in the study area, individuals in this study did not move between sites and/or habitat types (A.M. González-Di Pierro, personal observation). 
147 breast height) to determine if resource availability (food availability, Tutin et al., 1997; Doran et

148 al., 2002) differed between habitats (fragments and continuous forest). Within each site (three

149 fragments and three continuous forest sites), we randomly located ten $50 \times 2 \mathrm{~m}$ transects $(0.1 \mathrm{ha})$

150 to sample trees (following Gentry, 1982). We minimized edge effects by locating all transects at

151 least $100 \mathrm{~m}$ from the edge. We calculated the importance value index (IVI) of each species

152 within each habitat (Moore \& Chapman, 1986), which is an overall estimate of the percentage of

153 relative frequency of a plant species in the community. Differences in tree community attributes

154 (i.e., tree species richness, tree abundance, number of food tree species and IVI) between

155 continuous forest and fragments were analysed with $t$-tests after $\log (\mathrm{x}+1)$ or an arcsine

156 transformation of the data (the latter in the case of IVI). To test if differences in tree species

157 similarity (Jaccard's coefficient) were related to geographical distances among transects of each

158 study site, we performed Mantel tests (Sokal \& Rohlf, 1995).

HOWLER MONKEYS AND DIETARY COMPOSITION

This research complied with protocols approved by CONANP care committee (Comisión

162 Nacional de Áreas Naturales Protegidas) and DGVS (Dirección General de Vida Silvestre,

163 permission number SGPA/DGVS/07830). The collection of vegetation and feeding behaviour

164 data did not interfere with primates in any way. The black howler monkey (Alouatta pigra) is

165 present in Mexico, Guatemala and Belize, but most (ca. 80\%) of its distribution range is found in

166 Mexico. It is one of the largest Mesoamerican primates. The conservation status of the species is

167 “endangered" according to the IUCN Red List [http://www.iucnredlist.org/apps/redlist/search], 
168 and habitat loss is probably the most important threat affecting the populations. Howler

169 population density within the MABR is 0.13 individuals/ha, but within the study fragments ( 3 to

1706 ha, MCR) population density averaged 1.3 individuals/ha. Home-range size of black howlers in

171 continuous forest is $<25$ ha (Estrada, Van Belle \& García, 2004).

Dietary composition of howler monkeys was studied during a period of 18 months: three

months in the dry season from February to April of 2006, 2007 and 2008 and three months in the

174 rainy season from August to October of the same three years. We did not examine between

175 seasons and/or year changes in the food availability for primates because we needed a large and

176 complete data set in which all plant species and age and sex classes were represented to construct

177 the ecological networks. Feeding behaviour was documented during three consecutive days once

178 every three weeks, using five minutes of focal animal sampling (Altmann, 1974; Martin \&

179 Bateson, 1991). Each individual was recognized by characteristically unique marks on their skin 180 and hair. Monkeys were systematically observed from 7:00 am to 17:30 pm.

At the beginning of the study, we categorized the focal individuals by age and sex class

182

183

into six groups as follows: adult male, adult female (adults are full-grown individuals with

conspicuous sexual organs; males have an enlarged, noticeable hyoid bone); juvenile male and

female (juveniles are completely independent from adult females but not yet full-grown); and

male and female infant (infants depend on their mothers for locomotion and feeding, in some

instance). To construct the ecological networks, individuals were kept in their initially designed

age and class category despite the fact that infants were more independent at the end of the study.

In continuous forest, we recorded 15 individuals: six adult females, four adult males, two

juveniles (female and male), two infant females and one infant male. In forest fragments, we

recorded a total of 18 individuals: five adult females, four adult males, four juvenile females, 
191 three juvenile males, one infant female and one male. Howler monkey population size and

192 structure remained unchanged in fragments and continuous forest during the course of the study.

193 There was no birth or death in any of the studied groups.

194 All howler monkey individuals were observed for the same period of time in each habitat 195 type. The effect of habitat on feeding time and on the usage of different plant items was analysed 196 by comparing the fraction of time spent consuming different plant items (i.e., flowers, petioles, 197 young and mature leaves, mature and immature fruits and bark) within continuous forest and 198 forest fragments with a nested-ANOVA of angular transformed data. Data were analysed using 199 the statistical program SigmaStat for Windows 3.5. Furthermore, we refer to a preferred food 200 (i.e., an over selected food) as those plant species and items selected (usage) disproportionately 201 often relative to their abundance (availability) and to a fallback food as those plant species and 202 items that howler monkeys utilized when preferred foods are scarce (Marshall \& Wrangham, 203 2007). Typically, fallback foods are plant species and items of low preference but high 204 importance in the diet (e.g., liana leaves). Plant items of high importance are those most

205 frequently consumed regardless of their nutritional quality; whereas preferred items are those of 206 high quality, with quality defined as rate of energy return to an organism (e.g., ripe fleshy fruits). 207

\section{NETWORK METRICS}

We used the NODF metric (nestedness metric based on overlap and decreasing fill,

210 Almeida-Neto et al., 2008) to evaluate whether or not the diets of more selective monkeys represent subsets of the diets of monkeys that consumed a broader based diet for each habitat.

212 Because not all age and sex classes were present in all sites, we pooled individuals present within 213 each habitat type (fragments and continuous forest) to construct the networks from an 
214 intrapopulation perspective. $N O D F$ is recommended in ecological network analysis because it is

215 less prone to type I errors (Almeida-Neto et al., 2008). We generated theoretical matrices to test

216 the significance of the nestedness observed against null distributions of these values generated by

217 the Null Model II (Bascompte et al., 2003) in ANINHADO software (Guimarães \& Guimarães,

218 2006). We generated random matrices to test the significance of nestedness according to the Null

219 Model II by using functions within the software ANINHADO ( $n=1000$ randomizations for each

220 network). In this null model, the probability of occurrence of an interaction is proportional to the

221 number of interactions of both plant species and monkey individuals (Bascompte et al., 2003). In

222 our intrapopulation networks, plant species and monkeys are depicted as nodes, and their feeding

223 interactions are depicted by links describing the use of plant species by individuals. Our

224 qualitative approach in calculating nestedness decreases the probability of overestimating the

225 amount of resources (e.g., leaves vs. fruits) ingested by monkeys (Dáttilo et al., 2014).

226 Biologically, nestedness describes the organization of niche breadth in which more nested

227 networks tend to have the highest niche overlap (Blüthgen, 2010).

Other network parameters considered in the analysis were as follows: (i) mean linkage

level (mean number of links/interactions per species); (ii) connectance (the proportion of realized

230 links of the total possible in each network, defined as the sum of links divided by the number of

231 cells in the matrix); (iii) interaction diversity (based on the Shannon diversity index); and (iv)

232 resource selectivity at the network level $\left(\mathrm{H}_{2}^{\prime}\right)$. This selectivity index ranges from 0 (extreme

233 generalization) to 1 (extreme specialization) and is extremely robust with changes in sampling

234 intensity and the number of interacting species (Blüthgen et al., 2006). Network features were

235 estimated with the Bipartite package (Dormann, Gruber \& Group, 2011). Network plots were 
236 obtained by using Bipartite in 'R' (Dormann, Gruber \& Group, 2011; R Development Core

237 Team, 2011).

238

The categorical core $v s$. periphery analysis was used to describe plant species as core

239 (generalist species, those with the most interactions) or peripheral (those with fewer interactions)

240 components of the network. Core-periphery analyses were performed with UCINET for

241 Windows 6.0 (Borgatti, Everett \& Freeman, 1999), which performs two routines for detecting

242 core-periphery structures in bipartite graphs ( $n=20$ runs/network) and obtains the percentage of

243 occurrence of core-periphery species (see Borgatti et al., 1999; Díaz-Castelazo et al., 2010).

Results

Overall, we found that important food resources, including plant species and items,

changed with habitat type, and age and sex classes indicating that forest fragmentation affects the

247 feeding behaviour and level of resource selectivity of howler monkey populations in our study

248 sites.

Continuous forest and fragments presented similar tree species richness and density

252 (diameter at breast height $>10 \mathrm{~cm}$ ), similar numbers of tree species consumed by howler

253

monkeys and a similar IVI of food species (for all cases $t<2, \mathrm{df}=5, P>0.05$; Table I). Tree

254 species' similarity (Jaccard's coefficient) between continuous forest and fragments was $c a$. $70 \%$.

255 The Mantel test showed no significant association between tree species similarity and

256 geographical distances within and between habitat types $\left(t_{\propto}=0.57, P=0.60\right)$ : species were as 
257 likely to be found in 0.1 ha blocks close together as in those far apart. Fragments and continuous

258 forest shared $50 \%$ of the 10 tree species with the greatest importance value index (IVI), all of

259 which are consumed by howler monkeys (Table II).

HOWLER MONKEY DIETARY COMPOSITION

Overall, the total time spent making focal observations in fragments was 167.30 hours but was 146.66 hours in continuous forest because there were more individuals in fragments. Howler monkeys inhabiting forest fragments spent more time foraging (61.22 hours or $36.74 \%$ of the time) than those monkeys inhabiting continuous forest (39.55 hours or $26.52 \%$ of the time). Adults and juveniles in forest fragments spent more time foraging (adults, 46.14 hours; juveniles, 14.96 hours) than adults and juveniles in continuous forest (adults, 31.30 hours; juveniles, 5.56 hours); whereas in continuous forests infants spent more time foraging (2.80 hours) than infants present in forest fragments ( 0.12 hours). We found 30 plant species consumed for all age and sex classes in forest fragments and 27 in continuous forest (Figure 1, Table III). A total of 37 plant species and seven plant items (i.e., bark, immature fruits, flowers, mature fruits, immature

272 leaves, mature leaves and petioles as in Table III) were consumed in both habitats. These 273 included 32 species of trees, four species of woody lianas (Abuta panamensis, Bignonaceae sp., 274 Macherium sp. and Malpighiaceae sp.) and one species of a climbing herb (Araceae sp.). The 275 time devoted to consuming different plant items was similar for both habitats $\left(F_{1,13}=0.53, P=\right.$ 0.49), while plant items within habitats were consumed with significantly different frequency

277 (nested-ANOVA $F_{6,13}=13.13, P=0.003$ ). Overall, the plant items consumed with significantly greatest frequency (number of records per feeding time) were mature fruits and immature leaves 
279 for both habitat types (Figure 1). Feeding time changed among plant items between habitat types

280 as follows: mature fruits in continuous forest, $54.5 \% v s .37 .6 \%$ in forest fragments; immature

281 leaves, $31.0 \%$ vs. $56.2 \%$; immature fruits, $1.2 \%$ vs. $5.0 \%$; petioles, $6.2 \%$ vs. $0.5 \%$; mature

282 leaves, $3.8 \%$ vs. $0.8 \%$; and finally bark, $2.3 \%$ and flowers, $0.73 \%$ only in continuous forest.

283 Not all items were consumed in all plant species and habitats (Table III); in continuous forest

284 flowers (i.e., Machaerium sp.) were only consumed by females of all ages, whereas bark (i.e.,

285 Licania platypus) was only consumed by adult and infant females and by adult males. In

286 continuous forest, howlers spent more time eating mature fruits (more than $50 \%$ ) followed by

287 immature leaves (31\%), regardless of age-class. By contrast, in fragments, adults and juveniles

288 of both sexes spent more time consuming immature leaves $(50 \%)$ followed by mature fruits

$289(30 \%)$, whereas infants spent all of their time eating immature leaves.

290

291

292

293

294

295

296

297

298

299

300

\section{HOWLER MONKEY-PLANT NETWORKS}

We found a significant nested pattern in our howler monkey-plant network in both continuous forest (observed matrix: $N O D F=51.41$; mean \pm SD of simulated matrices: $N O D F=$ $44.78 \pm 3.48 ; P=0.04$ ) and fragment habitats (observed matrix: $N O D F=62.42 ;$ mean $\pm \mathrm{SD}$ of simulated matrices: $N O D F=45.71 \pm 2.89 ; P=0.01$ ) (Figure 2 and Table IV). Network attributes for the two habitats presented similar values of connectance, links per species, interaction diversity and resource selectivity. We found, however, lower links per species in continuous forest than in forest fragments, which probably generated greater resource selectivity and specialization in continuous forest (Table IV).

Species turnover as core/periphery components in fragments and continuous forests networks was very high as plant species fluctuated between habitats as core or periphery 
301 components (Table III). There were, however, three strict core species (i.e., A. hottlei, $B$.

302 alicastrum and D. guianense) and one strict peripheral species (i.e., Schizolobium arboreum).

303 The liana species Bignonaceae sp., Macherium sp., and the tree Cojoba arborea were core

304 species in fragments but periphery in continuous forest, whereas the tree species Albizia

305 leucocalyx, Brosimum lactescens and Garcinia intermedia were core species in continuous forest

306 but periphery in fragments. Not all common food tree species were those preferred by howler

307 monkeys in the network analysis (Table II, III). For instance, Ficus sp. was a core species in

308 forest fragments and peripheral in continuous forest, whereas Ficus tecolotensis was core in

309 continuous forest and peripheral in forest fragments. Moreover, P. bicolor was a core species for

310 continuous forest and fragments; however, it is not within the 10 tree species with the highest

311 importance value index (IVI) in either habitat (Table II).

\section{Discussion}

Overall, we observed that resource choice in fragments was lower within howler monkey populations, despite the presence of preferred plant food species for primates in both habitat types; their relatively low selection may have been driven by habitat attributes such as the

317 relative scarcity of the most favoured feeding plant species and items of forest fragments (Dias \&

318 Rangel-Negrín, 2015). Furthermore, we found a novel pattern of age, sex diet composition variation, indicating the presence of a sex, age class selectivity in the interaction between howler monkeys and the plant species they consume. This study is the first to show that age and sex

321 classes determine the structure of ecological networks in primate-plant interactions. Regardless

322 of habitat type, howler monkey populations are composed of both more selective and less 
323 selective individuals (Figure 2). In this monkey-plant system we have shown that less selective

324 individuals (i.e., adult males and females) consumed large amounts of resources independent of

325 type and availability, thus building a cohesive network to which more selective individuals were

326 attached (i.e., male and female infants) (Bascompte et al., 2003). Thus, as "generalist"

327 consumers, adults maintain the stability of the network.

\section{HABITAT, FOOD CHOICE AND AVAILABILITY} species turnover as core-periphery between continuous forest and fragments was evident in the consumption of Abuta panamensis, Bignonaceae sp., Brosimum lactescens, Cojoba arborea and Macherium sp. (Table III). All except B. lactescens were core species in fragments and peripheral in continuous forest. One unidentified species of Ficus sp. had a higher importance value index in both habitats; however, howler monkeys consumed it more often in fragments than in continuous forest. Several fig species are common and very important in the diet of several Neotropical primate species in different habitat types (Chaves, Stoner \& ArroyoRodríguez, 2012; Dáttilo et al. 2014).

The preferred plant species and items in continuous forests are limited or unavailable in fragments. Therefore, howler monkeys in fragments may rely on resources of relatively low preference (fallback foods) to fulfil their nutritional requirements (Marshall \& Wrangham, 2007). Plant parts or items of liana species as well as immature fruits and leaves of tree species were more frequently consumed in fragments than in continuous forest (Figure 1). In preserved

344 forests, howler monkeys are known to select large ripe fruits and immature leaves that are more 
345 easily digested (Leighton, 1993; Behie \& Pavelka, 2015). Lianas in fragments, by contrast, are

346 typically abundant and important in the diet of howler monkeys, but some of their plant parts or

347 items may provide low rates of energy gain when compared to preferred foods. Forest

348 fragmentation is known to increase the mortality of large fruit trees, to favour the proliferation of

349 several liana species and to negatively affect tree phenology (reduced fruit set; Laurance et al.,

350 2001; Chaves, Stoner \& Arroyo-Rodríguez, 2012).

Fragmentation affects the availability of mature fruits to primates through reduction in the

352

353

354

355

356

357

358

359

360

361

362

363

364

365

366

367

abundance and richness of large food trees, as larger trees produce more fruits than smaller ones

(Chapman et al., 1992; Laurance et al., 2001; Chaves, Stoner \& Arroyo-Rodríguez, 2012). The

decreased richness and abundance of large trees could negatively affect the distribution and abundance of many tropical primates, especially in the case of highly frugivorous species

(Chapman et al., 2007). A large proportion of tropical tree species produce fleshy fruits, allowing a year-round offer of resources that maintains several species of frugivores (Howe \& Smallwood, 1982; Fleming \& Kress, 2011). However, substantial changes in resource availability — both temporally and spatially_ within fragments may prevent howler monkeys from searching for and consuming their preferred plant items and species (e.g., ripe fruits).

Network attributes (nestedness, connectance, mean linkage density, interaction diversity) were similar between habitats. The higher consumption of preferred items in continuous forest might arise because howler monkeys are not limited and have the possibility to range freely and feed on the best resources (i.e., ripe fruits). In fragments, by contrast, they have to consume what is available, which may represent a restricted set of food choices (resulting in a greater overlap of plant species consumed items) causing the monkeys to spend more time feeding in fragments to fulfil their nutritional needs. 
Our findings indicate that individuals do not forage randomly when compared to null

models and that the diets of more selective monkeys (infants) represent subsets of plants and

372 items consumed by other group members (adults), implying that individuals differ in their

373 foraging strategies. Adult individuals are able to consume a wide range of plant species and

374 items and therefore make the strongest contribution to the nested structure of the system. Infants

375 may become generalists as they learn how to eat a wider range of plant species. Howler monkey

376 infants tended to be more selective, while juveniles consumed a more diverse set of plant species

377 than infants did. Adults, though, consumed the greatest variety of plant species and items. Male

378 and female infants tended to consume more plant species in continuous forest than in fragments,

379 whereas adult females were the most extreme "generalists" in the resulting networks (Dáttilo et

380 al. 2014). This study is the first one to show that the specialized diets of male and female infants

381 determined the nested structure of primate-plant networks in howler monkey populations.

382

383

384

385
Plant species making the greatest contribution to community nestedness (promoting asymmetry) were those species yielding greater fruit supplies and therefore a greater number of interactions and greater plant items consumed by howlers (Table III). These strict core species were not necessarily the most abundant in either habitat. According to the optimal foraging theory (Araújo et al., 2008, Araújo, Bolnik \& Layman, 2011), the individual niche depends on the availability of resources in the habitat; we indeed found that howler monkeys in fragments consume resources that were not utilized in continuous forest (e.g., lianas). 
howler monkeys and to link habitat fragmentation and howler monkey-resource interactions by

using a network approach. Our findings indicate that both age and sex class drive a nested

pattern in howler monkey-plant interactions; in this sense, this study is the first to provide a

mechanism that structures such networks. Furthermore, we found that within howler groups,

adults - particularly female adults- are likely to be the main seed dispersers for several old-

397

growth forest tree species (e.g., seeds $>1 \mathrm{~cm}$ in length) in the study region because their diet

consists primarily of mature fruits (Behie \& Pavelka, 2015; Dias \& Rangel-Negrín, 2015). In the

Lacandon forest, we were able to detect that howler monkeys inhabiting fragments displayed less

dietary selection because of the limited availability of preferred food readily available in

401

continuous forest, which may threaten their long-term persistence in disturbed habitats.

402

403

404

We warmly thank J.M. Lobato, H. Ferreira and A. Valencia for careful technical support.

405

406

\section{References}

407

408

409

410

\section{Ackowledgements}

Almeida-Neto M, Guimarães P, Guimarães PR Jr., Loyola D, Ulrich W, 2008. A consistent metric for nestedness analysis in ecological systems: reconciling concept and measurement. Oikos 117:1227-1239.

Altmann J. 1974. Observational study of behavior: Sampling methods. Behavior 49:227-267. 
411 Araújo MS, Guimarães PR Jr., Svanbäck R, Pinheiro A, Guimarães P, dos Reis SF, Bolnick DI.

412 2008. Network analysis reveals contrasting effects of intraspecific competition on individual $413 \quad$ versus population diets. Ecology 89:1981-1993.

414 Araújo, MS, Martins EG, Cruz LD, Fernandes FR, Linhares AX, dos Reis SF, Guimarães PR Jr. 415 2010. Nested diets: a novel pattern of individual-level resource use. Oikos 119:81-88.

416 Araújo MS, Bolnick DI, Layman CA. 2011.The ecological causes of individual $417 \quad$ specialisation. Ecology Letters 14:948-958.

418

419

420

421

422

423

424

425

426

427

428

429

430

431

432

Bascompte J, Jordano P, Melian CJ, Olesen J. 2003. The nested assembly of plant-animal mutualistic networks. Proceedings of Natural Academy of Science of USA 100:9383-9387.

Bascompte J, Stouffer DF. 2009. The assembly and disassembly of ecological networks. Philosophical Transactions of the Royal Society of Biology 364:1781-1787.

Behie AM, Pavelka MS. 2015. Fruit as a key factor in howler monkey population density: conservation implications. In Kowalewski MM, Garber PA, Cortes-Ortiz L, Urbani B, Youlatos D, eds. Howler Monkeys. Springer: New York, 357-382.

Blüthgen N. 2010. Why network analysis is often disconnected from community ecology: a critique and an ecologist's guide. Basic and Applied Ecology 11:185-195.

Bolnick DI, Svanback R, Fordyce JA, Yang LH, Davis JM, Hulsey CD, Forister ML. 2003. The ecology of individuals: incidence and implications of individual specialization. American Naturalist 161:1-28.

Borgatti SP, Everett MG, Freeman LC. 1999. UNICET 6 for Windows: software for social network analysis. Analytic Technologies, Harvard, Massachusetts. Analytic Technologies Inc. Online [URL] http://www.analytictech.com/downloaduc6.htm 
433 Borgatti SP, Mehra A, Brass DJ, Labianca G. 1999. Network analysis in the social sciences. $434 \quad$ Science 323:892-895.

435

436

437

438

439

440

441

442

443

444

445

446

447

448

449

450

451

452

Brent LJN, Lehmann J, Ramos-Fernández G. 2011. Social network analysis in the study of nonhuman primates: A historical perspective. American Journal of Primatology 73:720-730.

Cantor M, Pires MM, Longo GG, Guimarães PR, Setz EZF. 2013. Individual variation in resource use by opossums leading to nested fruit consumption. Oikos 122:1085-1093.

Chapman CA, Chapman LJ, Wangham R, Hunt K, Gebo D, Gardner L. 1992. Estimators of fruit abundance of tropical trees. Biotropica 24:527-531.

Chapman CA, Naughton Treves L, Lawes M J, Wasserman MD, Gillespie TR. 2007. Population declines of Colobus in Western Uganda and conservation value of forest fragments. International Journal of Primatology 28:513-528.

Chaves OM, Stoner KE., Arroyo-Rodríguez V. 2012. Differences in diet between spider monkey groups living in forest fragments and continuous forest in Mexico. Biotropica 44:105-113.

Dáttilo W, Serio-Silva JC, Chapman C, Rico-Gray V. 2014. Highly nested diets in intrapopulation tropical monkey-resource food webs. American Journal of Primatology 76:670-678.

De Jong BHG, Ochoa-Ganona S, Castillo-Santiago MA, Ramírez-Marcial M, Cairns MA. 2000.Carbon flux and patterns of land-use/land-cover change in the Selva Lacandona, Mexico. Ambio 29:504-511. 
453 Dias PAD, Rangel-Negrín, A. 2015. Diets of howler monkeys. In Kowalewski MM, Garber

454 PA, Cortes-Ortiz L, Urbani B, Youlatos D, eds. Howler Monkeys. Springer: New York, 21$455 \quad 56$.

456 Díaz-Castelazo C, Guimarães PR Jr., Jordano P, Thompson JN, Marquis RJ Rico-Gray V. 457 2010.Changes of a mutualistic network over time: reanalysis over a 10-year period. Ecology $458 \quad 91: 793-801$.

Doran DM, McNeilage A, Greer D, Bocian C, Mehlman P, Shah N. 2002. Western lowland gorilla diet and resource availability: New evidence, cross-site comparisons, and reflections on indirect sampling methods. American Journal of Primatology 58:91-116.

Dormann CF, Gruber B, Group R, 2011. Package Bipartite: visualizing bipartite networks and calculating some ecological indices. R Statistical Software. Available at http://www.r-

Estrada A, Van Belle S, García del Valle Y. 2004. Survey of black howler (Alouattapigra) and spider (Ateles geoffroyi) monkeys along the Río Lacantún, Chiapas, Mexico. Neotropical Primates 12:70-75.

Fleming TH, Kress WJ. 2013. The ornaments of life: coevolution and conservation in the tropics. University of Chicago Press. ISBN: 9780226253411

Fuentes-Montemayor E, Cuarón AD, Vázquez-DomÍnguez E, Benítez-Malvido J, ValenzuelaGalván D, Andresen E. 2009. Living on the edge: roads and edge effects on small mammal populations. Journal of Animal Ecology 78:857-865. 84. 
475 González-Di Pierro AM, Benítez-Malvido J, Méndez-Toribio M, Zermeño I, Arroyo-Rodríguez

476 V, Stoner KE, Estrada A. 2011. Effects of the physical environment and primate gut passage

477 on the early establishment of Ampelocera hottlei Standley in Rain Forest Fragments.

$478 \quad$ Biotropica 43:59-466.

479 Guimarães PR, Guimarães P. 2006. Improving the analyses of nestedness for large sets of 480 matrices. Environmental Modelling \& Software 21:1512-1513.

481 Howe HF, Smallwood, J. 1982. Ecology of seed dispersal. Annual Review of Ecology and $482 \quad$ Systematics 13:201-228.

Isabirye-Basuta GM, Lwanga JS. 2008. Primate populations and their interactions with changing habitats. International Journal of Primatology 29:35-48.

Jones, CB. 2005. Behavioral flexibility in primates: causes and consequences. Springer: New $486 \quad$ York.

Laurance WF, Pérez-Salicrup D, Delamônica P, Fearnside PM, D'Angelo S, Jerozolinski A,

488 Pohl L, Lovejoy TE. 2001. Rain forest fragmentation and the structure of Amazonian liana communities. Ecology 82:105-116.

490

Leighton M. 1993. Modeling diet selectivity by Bornean orangutans: Evidence for integration of 491 multiple criteria for fruit selection. International Journal of Primatology 14:257-313.

492

Marsh LK, Loiselle BA. 2003. Recruitment of black howler fruit trees in fragmented forests of 493 Northern Belize. International Journal of Primatology 24:65-86. Journal of Primatology 28:1219-1235. 
496 Martin P, Bateson P. 1991. Measuring Behaviour: An Introductory Guide. Cambridge

$497 \quad$ University Press.

498 Medellín R. 1994. Mammal diversity and conservation in the Selva Lacandona, Chiapas,

499 Mexico. Conservation Biology 8:780-799.

500 Moore PD, Chapman SB. 1986. Methods in Plant Ecology. Blackwell Scientific: Oxford.

501 Petchey OL, Morin PJ, Olff H. 2009. The topology of ecological interaction networks: the state

502 of the art. In Verhoef HA, Morin PJ, eds. Community Ecology: Processes, Models, and

503 Applications. Oxford University Press, 7-22.

504 Pires MM, Guimarães PR Jr., Araújo MS, Giaretta AA, Costa JCL, dos Reis SF. 2011. The

505 nested assembly of individual resource networks. Journal of Animal Ecology 80:896-903.

506 R Development Core Team, 2011. R: A language and environment for statistical computing. R

507 Foundation for Statistical Computing, Vienna, Austria. Available at http://www.R-

$508 \quad$ project.org.

509 Rivera A, Calmé S. 2006. Forest fragmentation and its effects on the feeding ecology of black

510 howlers (Alouatta pigra) from the Calakmul area in Mexico. In Estrada A, Garber PA,

511 Pavelka MSM, Luecke L, eds. New perspectives in the study of Mesoamerican primates:

512 Distribution, ecology, behaviour and conservation. Kluwer: New York, 189-213.

513 Sokal R, Rohlf JH. 1995. Biometry. Freeman, New York.

514 Stevenson PR, Pineda M, Samper T. 2005. Influence of seed size on dispersal patterns of woolly 515 monkeys (Lagothrix lagothricha) at Tinigua Park, Colombia. Oikos 110:435-440. 
516 Tinker MT, Guimaraes PR, Novak M, Marquitti FMD, Bodkin JL, Staedler M, Bentall G, Estes

517 JA. 2012. Structure and mechanism of diet specialisation: testing models of individual

518 variation in resource use with sea otters. Ecology Letters 15:475-483.

519 Tutin CEG, Ham RM, White LJT, Harrison MJS. 1997. The primate community of the Lope

520 Reserve, Gabon: Diets, responses to fruit scarcity, and effects on biomass. American Journal

521 of Primatology 42:1-24.

522

523

524

525

526

527

528

529 
530 Table I. Tree community (diameter at breast height $>10 \mathrm{~cm}$ ) attributes in continuous forest and

531 forest fragments inhabited by howler monkeys (Alouatta pigra) in the Lacandonian rain forest,

532 Chiapas, Mexico. The values are the average $( \pm \mathrm{SD})$ of ten $50 \times 2 \mathrm{~m}$ transects $(0.1 \mathrm{ha})$ in each of

533 three forest fragments and three continuous forests. Tree community attributes did not differ

534 significantly between habitat types (for all cases $t<2, \mathrm{df}=5, P>0.05$ ).

\begin{tabular}{lcc}
\hline Tree attributes & Continuous Forest & Forest Fragments \\
\hline Mean tree species richness $( \pm \mathrm{SD})$ & $33.7(4.7)$ & $33.3(2.1)$ \\
Mean number ( $\pm \mathrm{SD})$ of primate- & $16.0(3.1)$ & $12.0(0.6)$ \\
dispersed tree species & & $137(5.5)$ \\
Mean density of trees $(\mathrm{dbh}>10 \mathrm{~cm})$ & $141(16.4)$ & 6.5 \\
IVI of food species & 6.7 &
\end{tabular}

535 The importance value index (IVI) was calculated by summing the density, the frequency and

536 basal area of each species within each habitat (Moore and Chapman, 1986).

537

538

539

540 
542 Table II. The ten tree species with the highest importance value index (IVI) in continuous forest

543 and forest fragments occupied by howler monkeys (Alouatta pigra) at the Lacandonian rain

544 forest, Mexico. All tree species are present in the diet of howler monkeys.

\begin{tabular}{lll}
\hline Family & Species & IVI \\
\hline Continuous Forest & Brosimum alicastrum & 0.52 \\
Moraceae & Guarea excelsia & 0.40 \\
Meliaceae & Ficus sp. & 0.36 \\
Moraceae & Ampelocera hottlei & 0.22 \\
Ulmaceae & Bursera simaruba & 0.19 \\
Burseraceae & Spondias mombin & 0.15 \\
Anacardiaceae & Trophis racemosa & 0.15 \\
Moraceae & Acacia usumacintensis & 0.13 \\
Fabaceae & Castilla elastica & 0.12 \\
Moraceae & Albizia leucocalyx & 0.11 \\
Fabaceae & &
\end{tabular}

Forest Fragments

Fabaceae

Dialium guianense

0.53

Moraceae

Brosimum alicastrum

0.46

Fabaceae

Pterocarpus bayesii

0.28

Ulmaceae

Ampelocera hottlei

0.26

Moraceae

Ficus sp.

0.21

Moraceae

Castilla elastica

0.19 
$\begin{array}{ll}\text { Chrysobalanaceae } & \text { Licania platypus }\end{array}$

\begin{tabular}{clc}
545 & Pouteria campechiana & 0.16 \\
Moraceae & Trophis racemosa & 0.15 \\
Meliaceae & Guarea excelsia & 0.11 \\
\hline
\end{tabular}


547 Table III. Occurrence of plant species in the core and in the periphery for each network

548 (continuous forest and fragments). The items consumed per plant species are indicated for each

549 habitat type. Plant items per species are arranged from left to right, with items at the far left

550 being the most consumed; where items are: $\mathrm{B}=$ bark, $\mathrm{IF}=$ immature fruit, $\mathrm{FL}=$ flower,

$551 \mathrm{MF}=$ mature fruit, $\mathrm{IL}=$ immature leave, $\mathrm{ML}=$ mature leave and $\mathrm{P}=$ petiole.

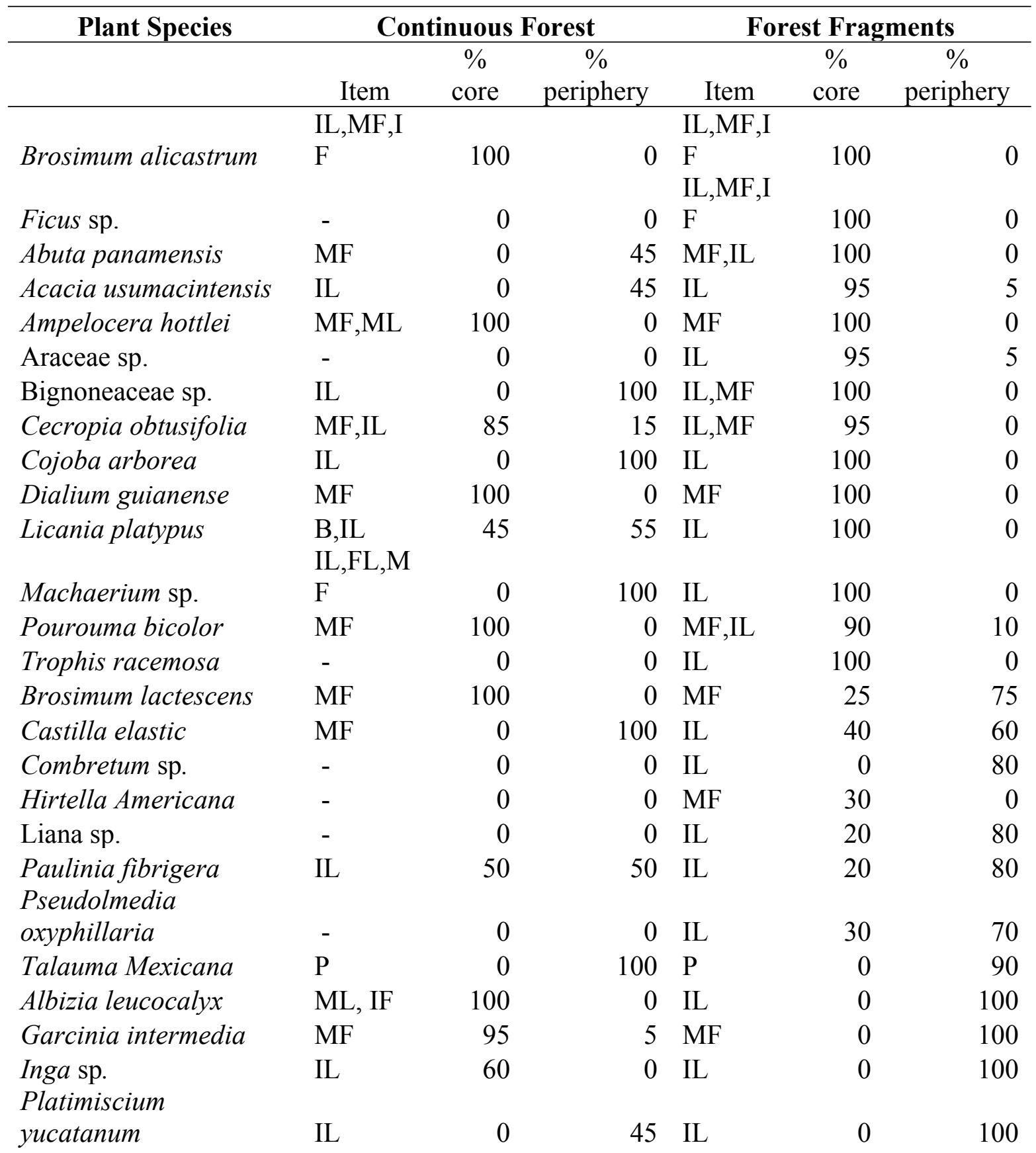




\begin{tabular}{llrrlrr} 
Sapindaceae sp. & - & 0 & 0 & MF & 0 & 100 \\
Schizolobium arboreum & P & 0 & 100 & P & 0 & 100 \\
Spondia mombin & - & 0 & 0 & MF & 0 & 100 \\
Bursera simaruba & - & 0 & 0 & IL & 0 & 100 \\
Ficus tecolotensis & MF,IL & 100 & 0 & - & 0 & 0 \\
Bravaisia sp. & IL,P & 55 & $45-$ & 0 & 0 \\
Maclura tinctoria & IL & 100 & $0-$ & 0 & 0 \\
Ficus yoponensis & IL & 0 & $100-$ & 0 & 0 \\
Lonchocarpus sp. & ML & 0 & $100-$ & 0 & 0 \\
Malpigiaceae sp. & FL & 30 & $70-$ & 0 & 0 \\
Zanthoxylum & & & & & 0 & 0 \\
riedelianum & IL & 0 & $100-$ & & \\
\hline
\end{tabular}


553 Table IV. Howler monkey-plant network attributes in continuous forest and forest fragments at 554 the Lacandon rain forest, Mexico; see methods for details.

\begin{tabular}{lcc}
\hline \multicolumn{1}{c}{ Network Metrics } & Continuous Forest & Forest Fragments \\
\hline No. of monkeys & 15 & 18 \\
No. of plant species & 27 & 30 \\
Nestedness (NODF-metric) $)^{\mathrm{a}}$ & 51.41 & 62.42 \\
Links per species & 3.76 & 4.08 \\
Connectance $(C)$ & 0.39 & 0.36 \\
Interaction diversity & 5.06 & 5.27 \\
Resource selectivity $\left(H_{2}{ }^{\prime}\right)$ & 0.28 & 0.22 \\
& & \\
\hline
\end{tabular}

$555 \quad{ }^{a}$ Both networks were significantly nested $(P<0.05)$.

556 
558 Figure 1. Diet composition of howler monkeys (Alouatta pigra) in continuous forest and

559 fragments according to percentage of total feeding time consuming different plant items.

560 Significant $(P<0.05)$ differences in the consumption of plant items is indicated with an asterisk

561 (*). The items consumed per plant species are indicated for each habitat type; where items are: B

$562=$ bark, $\mathrm{IF}=$ immature fruit, $\mathrm{FL}=$ flower, $\mathrm{MF}=$ mature fruit, $\mathrm{IL}=$ immature leave, $\mathrm{ML}=$ mature

563 leave and $\mathrm{P}=$ petiole.

564 Figure 2. Intrapopulation howler monkey-plant networks (Alouatta pigra) for (A) continuous

565 forest and (B) forest fragments. Each node represents one monkey (left) or plant species (right)

566 and lines represent monkey-plant interactions. Codes for $A$. pigra age-classes are the following:

567 light box= adult female; dark box = adult male; light triangle $=$ juvenile female; dark triangle $=$

568 juvenile male; light diamond= infant female; and dark diamond= infant male. 


\section{Figure 1.}

571

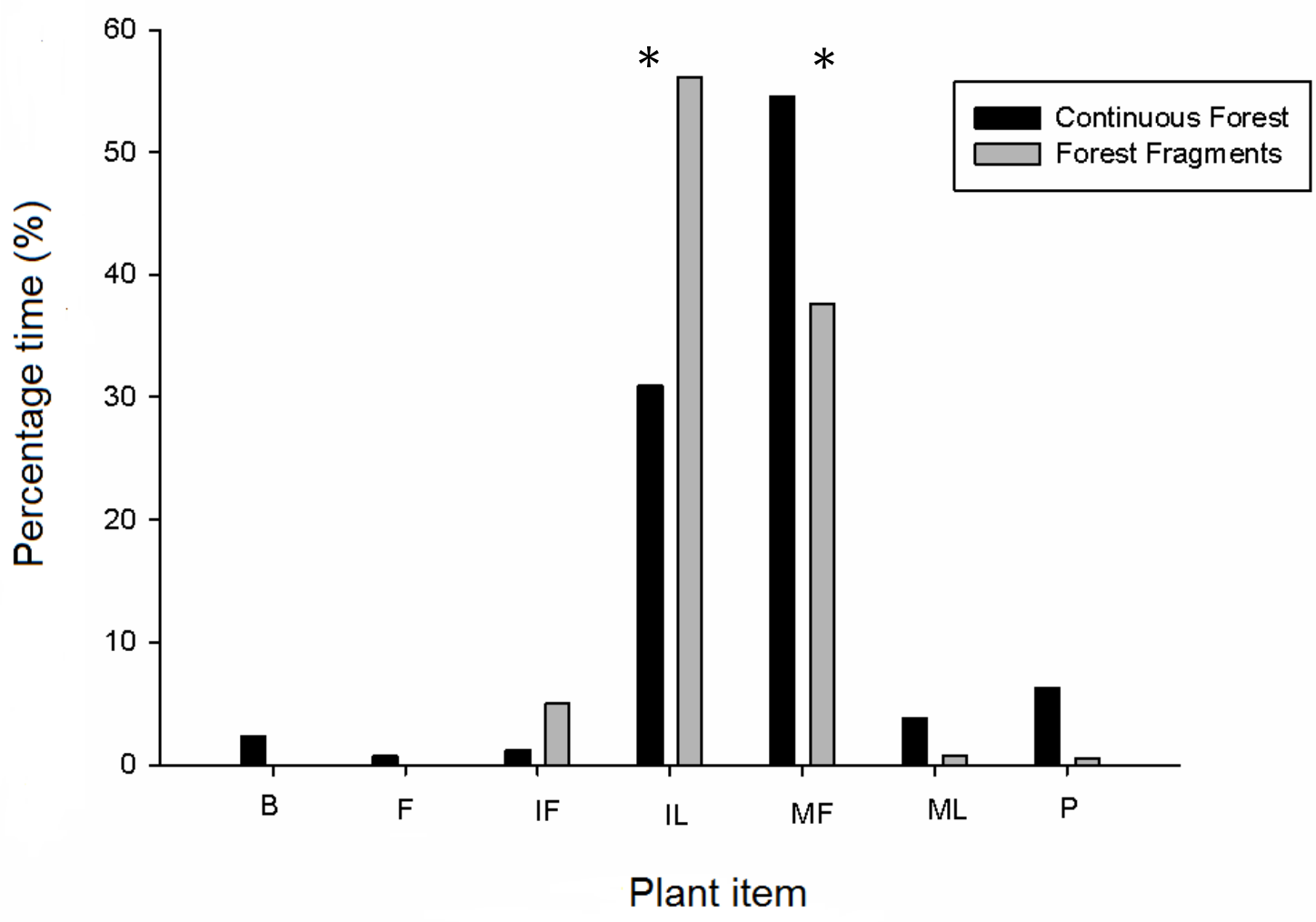


$574 \quad$ Figure 2 


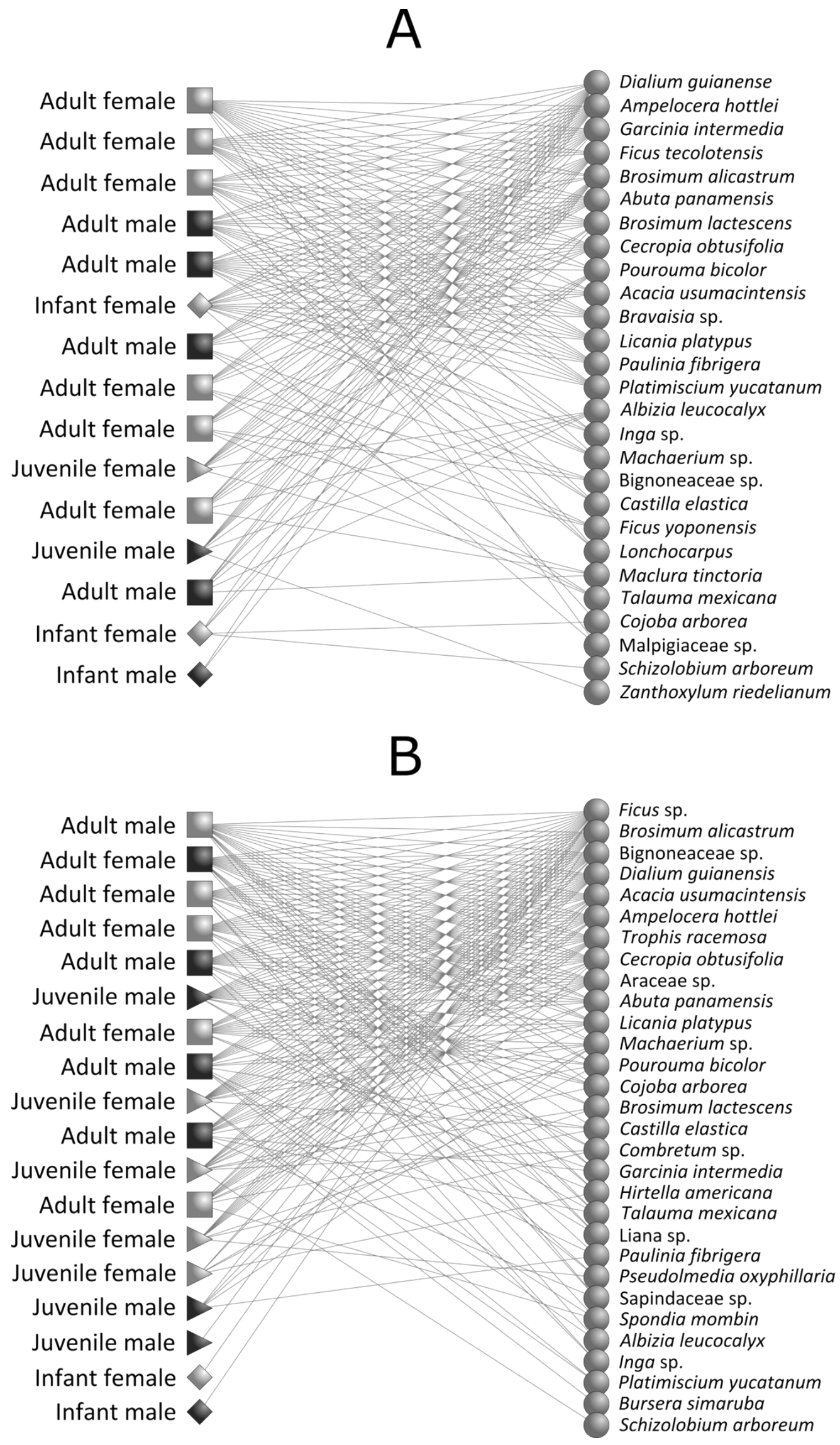

